\title{
Case Test of Citizen Participation in Complex Governance-Based on the Democracy Cube
}

\author{
Mengqi Shi \\ Zhou Enlai School of Government, Nankai University, Tianjin, China \\ Email: 2120182176@mail.nankai.edu.cn
}

How to cite this paper: Shi, M.Q. (2019) Case Test of Citizen Participation in Complex Governance-Based on the Democracy Cube. Open Journal of Social Sciences, 7 , 255-260.

https://doi.org/10.4236/jss.2019.710020

Received: October 8, 2019

Accepted: October 19, 2019

Published: October 22, 2019

Copyright $\odot 2019$ by author(s) and Scientific Research Publishing Inc. This work is licensed under the Creative Commons Attribution-NonCommercial International License (CC BY-NC 4.0). http://creativecommons.org/licenses/by-nc/4.0/

\begin{abstract}
In recent years, under the policy orientation of expanding public orderly political participation, the government has continuously strived to innovate the form and content of public participation and achieved good implementation results. In this paper, based on the democracy cube, we combine domestic democratic cases which are the representative participatory budget reform in the Xihu district of Nanchang, and discuss citizen participation issues from the perspectives of authority, participants and communication mode in detail.
\end{abstract}

\section{Keywords}

The Democracy Cube, Citizen Participation, Authority, Participants, Communication Mode

\section{Introduction}

Public participation first originated from direct democracy in ancient Greece. Since modern times, public administration has been controversial around "fairness first" or "efficiency first". The new public administration school, represented by Waldo and Frederickson, places greater emphasis on democratic values. Driven by the new public administration school, participatory budget reforms have quietly emerged in China. The report of the 19th National Congress of the Communist Party of China has repeatedly mentioned "protecting people's right to participate" and "equal participation of the people", which is enough to prove that the central government attaches importance to and supports the participatory budget reform. Zheng (2015) considers that the fundamental characteristic of the modern community governance structure is the participation of the government, social organizations and individual citizens [1]. Chen (2017) argues that the ordering of public participation should stand on China's contemporary context, promote the interaction between self-culture and other cul- 
tures, construct the model combining leading participation and progressive participation [2]. In view of this, we intend to select the representative public participation practice in China-the Participatory Budget of Xihu district in Nanchang, and use the theory of democratic cube to test the value of public participation from the perspectives of authority, participants and communication mode. It provides theoretical reference and practical enlightenment for the development of public participation in China.

\section{Theoretical Framework}

Archon Fung who is an associate professor of public policy at the Harvard University's Kennedy School of Government put forward the democracy cube (Figure 1) [3]. His article "Varieties of Participation in Complex Governance" presents the theoretical connotation of the democracy cube. On the basis of a vast number of case studies, Professor Archon Fung extracted the three most important issues of public participation in different democratic systems: Who participates? How do they communicate and make decisions? What is the connection between their conclusions and opinions on one hand and public policy and action on the other? Then using the rubric of a three-dimensional institutional space to explore participatory mechanisms that are suited to solve problems in contemporary governance: authority, participants and communication mode.

The author has offered a framework for thinking about the major design variations in contemporary participatory institutions. In addition, this article has many highlights. Firstly, the structure of the article is clear and understandable. The subtitle divides the article into several interrelated parts with strong logic.

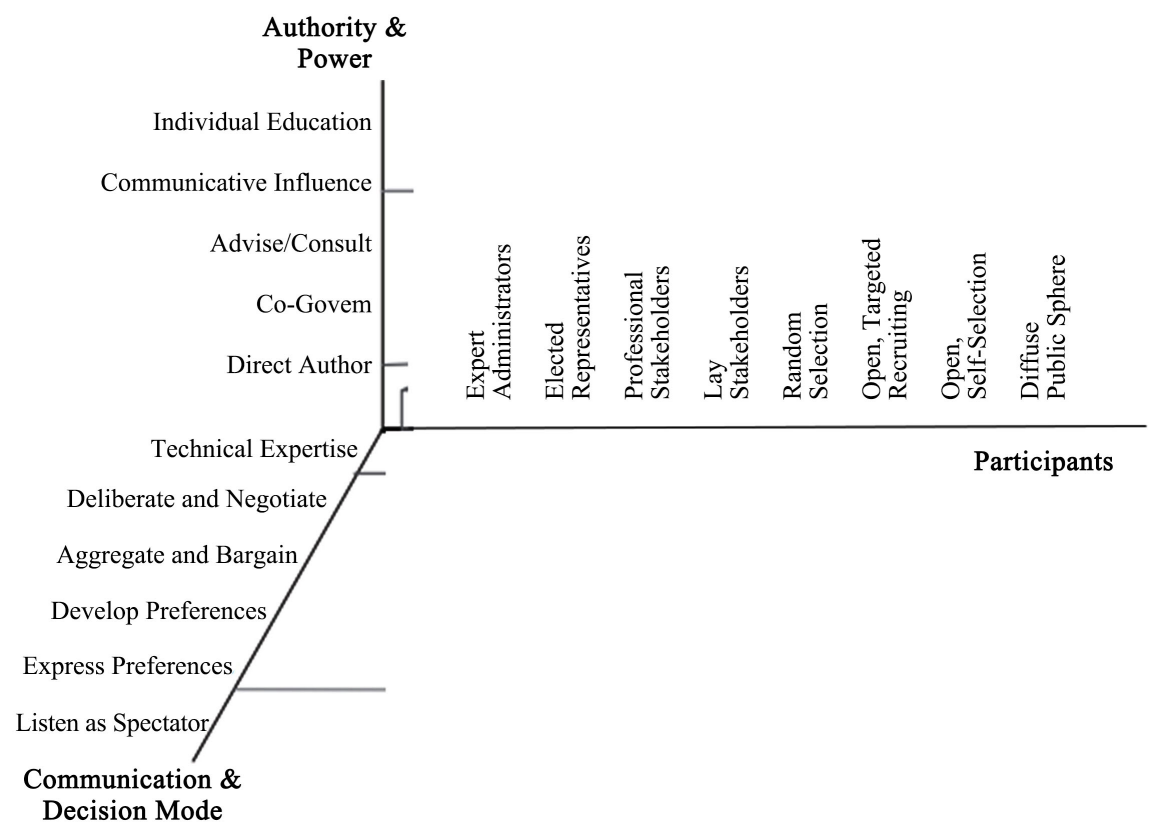

Figure 1. The democracy cube. 
The three dimensions and values of participation are discussed very clearly. Secondly, the author provides us with a theoretical framework, and introduces three dimensions of the framework and the three democratic values it serves in detail, this framework can cover all forms of participation. The author discovers the potential of democratic participation and calls for the rational design of popular participation to solve the problem of government failure. Thirdly, the author shows us some cube figures composed of three dimensions, in which different ways of participation can find their own position. Moreover, the author also uses many cases to explain the point of view, so that the article is convincing.

But every coin has two sides: The author only lists different ways of participation, but do not evaluate them, we just know what is self-selected, what is selectively recruit ... so we do not know which made the improvement of democratic participation lacked clear direction. Besides, the author only proposes a framework for explaining participation, but do not further suggest how this framework can promote better participation. Finally, the author ignores the challenge of participatory innovations aimed at effective governance. Although the number of participatory innovations seems to have proliferated in recent years, the results of many innovations are quite limited, even making them insignificant. We called it is the park bench problem. When authorizes citizens the power to decide which color to paint for their park benches, it will increase public participation, but it will not be done in a meaningful way, and it is considered to be inefficient to a certain extent. There are many different ways to restrict public participation, so many factors made citizens do not create a substantial role: the outcomes and the agenda of issues that they consider can be highly constrained, or the resources and authorities invested in a participatory process can be tiny. Now we based on the democracy cube, combining domestic democratic cases, discussing citizen participation issues from the perspectives of authority, participants and communication mode.

\section{Case Test of Citizen Participation in Complex Governance}

The case selected in this paper is a representative participatory budget reform in the Xihu district of Nanchang. First is Authority \& Power. On July 28, 2017, the Civil Affairs Bureau of Xihu district of Nanchang applied to the Xihu district government, hoping to conduct a participatory budget reform project with "Happiness" as the content of 21 communities in two streets, Guang Runmen Street and Nanpu Street. The reform project pilot, that is, through the citizens' proposals and democratic voting, to solve some livelihood projects that the community is concerned about. The Xihu district government fully supports the project and fully empowers the conditions required for participatory budgeting to the streets. The streets are based on local conditions, and give the necessary powers to the communities, which organizes and arranges all activities. In this way, the participatory budget reform completed the empowerment of grassroots 
organizations, including street empowerment and community empowerment, which laid the foundation for the official launch of the project and facilitated the participation of social organizations. Moreover, due to the empowerment of the district government, the streets responsible for the specific implementation can make the goal commitment of citizens to participate. And the goal commitment is giving the streets 1 million Yuan and the communities 0.3 million Yuan for the citizens' livelihood investment, and giving the decision power to the citizens completely. Therefore, there is an intrinsic connection between empowerment and goal commitment, which lays the foundation for stimulating the enthusiasm of citizen participation. The participatory budget reform firstly collects project proposals through street empowerment and community empowerment, and then holds round tables to vote after citizens have been negotiated and discussed. Next, through programmatic and project-based project selection, the quota budget and voting results are determined. Finally implements the livelihood project. Corresponding to the dimension of authority \& power in the democracy cube, the participatory budget reform in the Xihu district is mainly related to "Advise/Consult": officials preserve their authority and power but commit themselves to receiving input from participants. The stated purpose of most public hearings and many other public meetings is to provide such advice [3].

The next is Communication and Decision Mode. Only if the mode between the government and the public is in conformity with the norm, those public policies and governmental actions will be supported. At this time, those are considered to be legal [4]. Xiangshan Community of Xihu district took the lead in launching round table consultations, which means each table will elect a representative to introduce three supported proposals and persuade others to vote for them. Each citizen has up to 10 votes, and the results will be announced on the spot, which needs budget quotas, as well as preparation for the final vote Firstly, making ballots, which bases on the list of proposals. So, how to determine the quota? It follows the practice in Haikou City Meilan District, which is based on the high-to-low list, adding to budget quota. Different ballots community-project ballots and street project ballots, are distinguished by different colors. Polling stations are mainly set up in street and community workstations. Eligible citizens can vote up to 5 projects. It will be invalid, if more than 5 . The counting began at 9am on February 4, 2018 in the community workstations. Many citizens visited and supervised the site. The counting shall be based on the number of votes, and a list of votes shall be formed and reported to the street which will decide on the final results. On the morning of February 5, 2018, the street made a final confirmation of the voting list and decided on the final results. The projects which don’t exceed $¥ 300,000$ for the total community and 1 million for the total street were elected finally. Corresponding to the dimension of Communication \& Decision Mode in the democracy cube, the participatory budget reform in the Xihu district is mainly attached to "Aggregate and Bargain": participants know what they want, and the mode of decision making ag- 
gregates their preferences-often mediated by the influence and power that they bring-into a social choice. The exploration and give-and-take of bargaining allows participants to find the best available alternative to advance the joint preferences they have [3].

The third dimension is Participants Selection. The first is the recruitment of social organizations. According to existing experience, the participation of social organizations can play an important role in assisting the equal participation of citizens and promoting consultation, discussion and dialogue among citizens. The social organization of Xihu district in Nanchang is roughly divided into three parts: the alumni associations of universities in Nanchang, the existing social organizations in each community (mainly are entertaining social organizations, sporting social organizations), and there are also many volunteer associations established by universities such as Nanchang University [5]. Social organizations have played an active role in promoting citizens' participation and thus driving street participation, especially in promoting repeated consultations between citizens. Next is the round table negotiation stage. In the round table, participants are divided into 6 groups. Each with a table leader, a recorder, a technical consultant which is served by social organizations and 8 - 12 citizens. Everyone knows his place in the group. The leaders of the round table preside over the speeches and discussions in the group. The technical consultants guide, supplement and deepen the suggestions of the citizens, and assist the leaders of the round table to mobilize the enthusiasm of the citizens and record their suggestions. Then there is the budget quota and voting to determine the implementation project stage. Those as least 15 years of age, the community residents living in the pilot area, working in the community, and students attending the community can vote at the polling points in the community. It's worth noting that the turnout rates of the two streets of Nanpu and Guang Runmen are relatively high, exceeding $50 \%$. The difference is that Nanpu Street has a prior voting rate requirement, while Guang Runmen Street fully respects residents' willingness. In any case, after the district government's empowerment at the grassroots level and the mobilization of social organizations, the citizens gradually changed from passive to active, and the active participation of the citizens promoted the enthusiasm of the community and the streets, making the goal more satisfactorily achieved. In summary, corresponding to the dimension of Participant Selection in the democracy cube, the participatory budget reform in the Xihu district is mainly related to "selectively recruit" when recruiting social organizations. In the round table negotiation stage, it belongs to "lay stakeholder". In the stage of budget quota and voting to determine the implementation project is mainly attached to "randomly selected".

\section{Conclusions}

The participatory budget reform in Xihu District of Nanchang is centered on grassroots empowerment, social organization mobilization, and citizen partici- 
pation and their intrinsic association. Combined with the democracy cube for analysis, the role of the government in Xihu District of Nanchang is relatively weak. Although the street is the representative of the government, the street is basically governed under professional opinion, and there have few colors of administrative intervention. Meanwhile, the social organizations of Xihu district in Nanchang are relatively active, with various forms of social organizations, such as volunteers organized by universities. Their division of labor is detailed and organized, and they play an active role in mobilizing community citizens, screening of proposal projects. More importantly, due to the active involvement of social organizations, the enthusiasm of the community neighborhood committees has been promoted, which in turn has driven the initiative of street administration, and it is a bottom-up model.

We should realize that there is still no democratic participation practice that can simultaneously satisfy the three-dimensionality of public participation to the greatest extent. Whether such public participation practice will occur in the future is still unknown. However, in any case, participatory budgeting is a very important grassroots governance method and an important manifestation of local governance innovation [6]. Its sustainable operation and long-term influence require both an innovative macro-institutional environment and a micro-institutional mechanism. Thence, participatory budgeting will become an important driving force for promoting grassroots democratic governance in China.

\section{Conflicts of Interest}

The author declares no conflicts of interest regarding the publication of this paper.

\section{References}

[1] Zheng, J.J. (2015) Public Participation: Institutionalization of Community Governance and Social Autonomy. Study \& Exploration, 3, 69-73.

[2] Chen, F.L. and Chen, F.G. (2017) The Modern Propulsion of the Ordering of Public Participation: Logical Response Based on Chinese Context. Theory and Reform, 3, 42-50.

[3] Fung, A. (2006) Varieties of Participation in Complex Governance. Public Administration Review, 66, 66-75. https://doi.org/10.1111/j.1540-6210.2006.00667.x

[4] Gu, L. (2003) Governance in the Information Society-Research on Government Governance Concept and Governance Paradigm. Tianjin People's Press, Tianjin, 28.

[5] Yin, L. and Liu, W. (2019) Empowerment, Mobilization and Participation: The "Xihu Experience" of Participatory Budget Reform. Tribune of Study, 3, 65-72.

[6] Walker, A.P.P. (2013) Embodied Identity and Political Participation: Squatters' Engagement in the Participatory Budget in Brazil. Ethos, 2, 199-222.

https://doi.org/10.1111/etho.12015 